\title{
One-session combined technique for a recurrent rectal polyp: submucosal dissection and endoscopic full-thickness resection
}

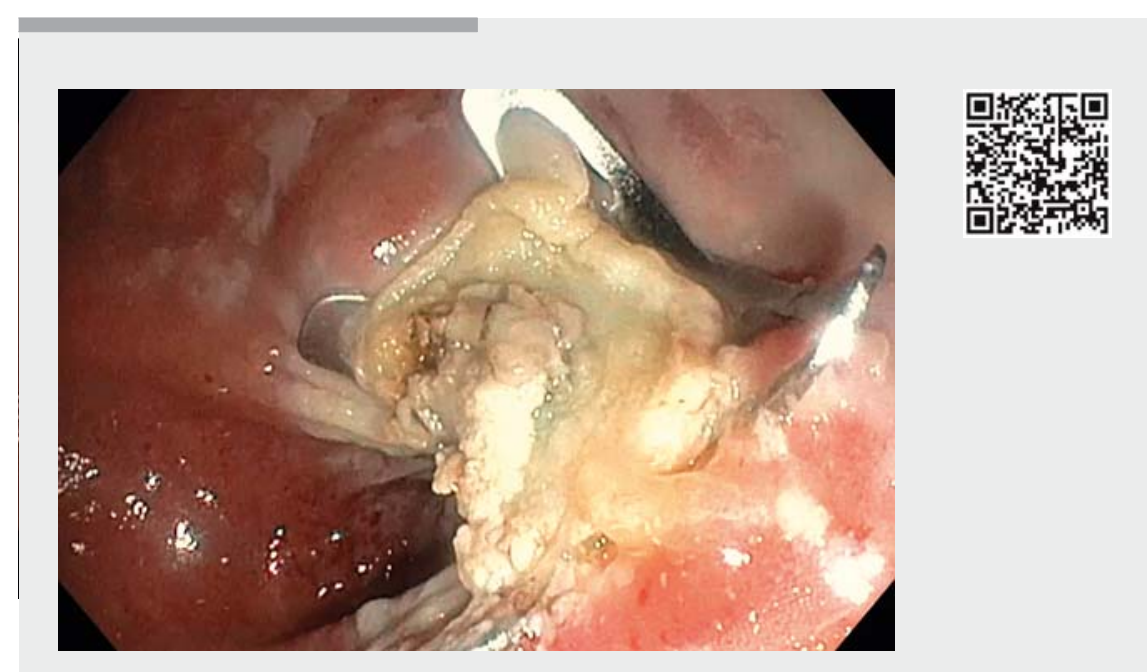

$\checkmark$ Video $1 \mathrm{~A}$ recurrent rectal polyp is successfully treated in a same-session combined approach using first endoscopic submucosal dissection (ESD) and then endoscopic fullthickness resection (EFTR).

The advent of endoscopic submucosal dissection (ESD) and endoscopic fullthickness resection (EFTR) have changed the treatment scenario for recurrent polyps, which represented one of the bigger challenges for endoscopists when endoscopic mucosal resection (EMR) was the only available technique. However, these two techniques have some limits: high grade fibrosis may reduce the possibility of performing ESD and increase the risk of perforation [1,2], while the size, thickness, and rigidity of the lesion, the mobility of the wall, and the location and grade of fibrosis may limit EFTR [3, 4]. Our aim was to evaluate the feasibility, efficacy, and safety of a single-session combined technique performing ESD and EFTR for adenomatous recurrence in the rectum.

In 2014, a 65-year-old man underwent EMR of a tubulovillous adenoma with low grade dysplasia (LGD) with a diameter of $40 \mathrm{~mm}$ in the rectum. The 3-year followup colonoscopy showed an adenomatous recurrence of $25 \mathrm{~mm}$, characterized by a sessile part and a flat part, positioned on the back of the second Huston's valve. ESD appeared difficult to perform alone because of the high grade fibrosis of the sessile portion, while an approach with EFTR was unfeasible because of the size, rigidity, and back-fold position of the flat part. Therefore, we decided to perform a partial ESD of the back-fold flat portion, thereby obtaining lesion mobility to allow performance of EFTR of the whole lesion ( Video 1).

Histologic examination of the resected lesion showed an en bloc specimen of tubulovillous adenoma with LGD and free resection margins (\$ Fig. 1). After 12 months of follow-up, there is no evidence of endoscopic or histologic recurrence ( Fig. 2).

In conclusion, this one-session combined endoscopic technique could represent a valid option for the resection of "hardto-treat" recurrent rectal polyps, thereby reducing the need for surgical treatment.

Endoscopy_UCTN_Code_TTT_1AQ_2AD

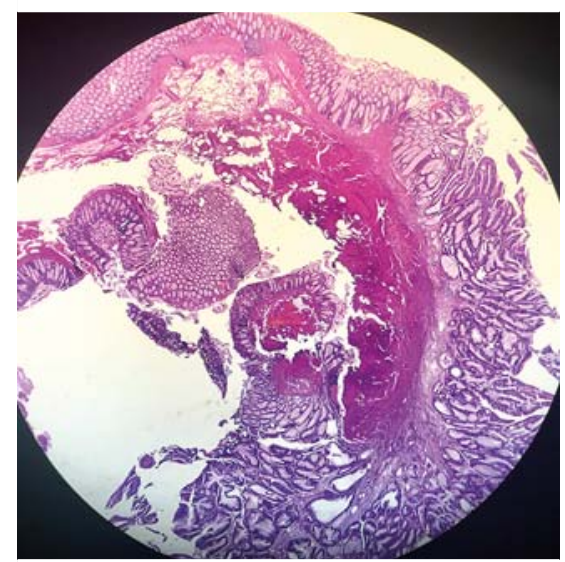

- Fig. 1 Histology of the resected en bloc specimen showing a tubulovillous adenoma with low grade dysplasia.

Competing interests

Vincenzo Cennamo: Olympus Italia, Olympus Europa, Euromedical, Novità Medicali.

The authors

Stefania Ghersi ${ }^{1}$, Marco Bassi ${ }^{1}$, Stefano Landi ${ }^{1}$, Cecilia Binda ${ }^{2}$, Emanuele Dabizzi ${ }^{1}$, Vincenzo Cennamo'

1 Unit of Gastroenterology and Operative Digestive Endoscopy, Bellaria Maggiore Hospital, AUSL Bologna, Italy

2 Department of Internal Medicine, Gastroenterology and Hepatology, Catholic University of Sacred Heart of Rome, A. Gemelli Hospital, Rome, Italy

\section{Corresponding author}

\section{Stefano Landi, MD}

Unit of Gastroenterology and Operative Digestive Endoscopy, Bellaria Maggiore Hospital, AUSL Bologna, BO, Italy Stefano.landi5@gmail.com 

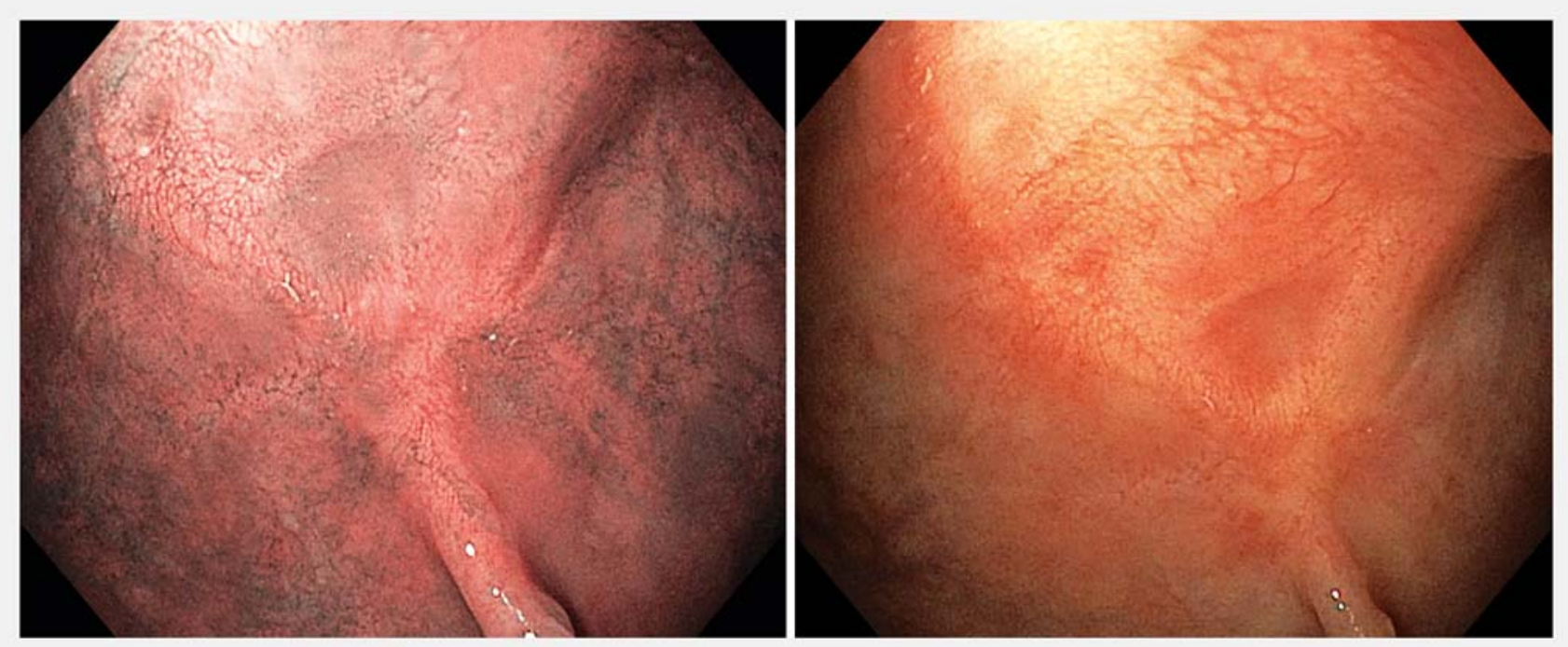

- Fig.2 Endoscopic views showing no evidence of recurrence at the 12-month follow-up.

\section{References}

[1] Saito Y, Yamada M, So E et al. Colorectal endoscopic submucosal dissection: Technical advantages compared to endoscopic mucosal re- section and minimally invasive surgery. Dig Endosc 2014; 26: $52-61$

[2] Kim ES, Cho KB, Park KS et al. Factors predictive of perforation during endoscopic submucosal dissection for the treatment of colorectal tumors. Endoscopy 2011; 43: $573-578$

[3] Schmidt A, Bauerfeind P, Gubler C et al. Endoscopic full-thickness resection in the colorectum with a novel over-the-scope device: first experience. Endoscopy 2015; 47: 719 725
[4] Andrisani G, Pizzicannella M, Martino M et al. Endoscopic full-thickness resection of superficial colorectal neoplasms using a new over-the-scope clip system: A single-centre study. Dig Liver Dis 2017; 49: 1009-1013

\section{Bibliography}

DOI https://doi.org/10.1055/a-0851-6657

Published online: 5.3.2019

Endoscopy 2019; 51: E120-E121

(c) Georg Thieme Verlag KG

Stuttgart · New York

ISSN 0013-726X

\section{ENDOSCOPY E-VIDEOS}

https://eref.thieme.de/e-videos

Endoscopy E-Videos is a free access online section, reporting 靣䧴: on interesting cases and new techniques in gastroenterological endoscopy. All papers include a high quality video and all contributions are freely accessible online.

This section has its own submission website at https://mc.manuscriptcentral.com/e-videos 